\title{
Controle de Plantas daninhas na Produção de Mudas de Plantas ORnamentais ${ }^{1}$
}

\author{
Weed Control in Ornamental Plant Seedling Production
}

\begin{abstract}
FREITAS, F.C.L. ${ }^{2}$, GROSSI, J.A.S. ${ }^{3}$, BARROS, A.F. ${ }^{4}$, MESQUITA, E.R. ${ }^{4}$ e FERREIRA, F.A. ${ }^{5}$
RESUMO - Este trabalho teve como objetivo avaliar a eficácia do oxyfluorfen no controle da brilhantina (Pilea microphylla) na produção de mudas de plantas ornamentais. Foram conduzidos dois experimentos, no delineamento de blocos ao acaso, no esquema fatorial $3 \times 7$, com três repetições. Um dos experimentos foi constituído por mudas de três espécies de plantas ornamentais - copo-de-leite (Zantedeschia aethiopica), estrelitzia (Strelitzia reginae) e palmeira-australiana (Archontophoenix cunninghamiana) - e sete doses de oxyfluorfen $(0$, 24, 72, 144, 216, 288 e $\left.360 \mathrm{~g} \mathrm{ha}^{-1}\right)$ pulverizadas em área total, e o outro, pelas mesmas espécies e sete concentrações de oxyfluorfen $(0,00000$ 0,00036, 0,00072, 0,00144, 0,00288, 0,00576 , e $0,01152 \%$ do i.a.), aplicadas em pulverização dirigida à brilhantina, sem atingir as folhas das mudas de plantas ornamentais. Cada unidade experimental foi constituida de um vaso com uma muda de planta ornamental, infestado com brilhantina. Aos 15, 30 e 60 dias após aplicação do herbicida (DAA), foram realizadas avaliações visuais de toxidez nas plantas ornamentais e controle de brilhantina. Para aplicação em área total, os vasos com plantas de palmeira-real-australiana demandaram doses mais elevadas do herbicida, devido à maior área foliar desta espécie por ocasião da aplicação, promovendo o "efeitoguarda-chuva". Ainda nessa modalidade de aplicação, verificaram-se sintomas de intoxicação, considerados leves, nas mudas de plantas ornamentais, porém mais evidentes nas plantas de palmeira-australiana. Em aplicação dirigida, não houve interação entre fatores, espécie e concentração do herbicida, nem diferença no comportamento do herbicida entre as espécies para as características avaliadas. Não se observou intoxicação nas plantas ornamentais em nenhum dos tratamentos avaliados, na aplicação dirigida. Verificou-se controle eficiente de brilhantina, acima de 90\%, a partir das doses de 300, 320 e $340 \mathrm{~g} \mathrm{ha}^{-1}$ de oxyfluorfen, para plantas de copo-de-leite, estrelítzia e palmeira-australiana, respectivamente, $\mathrm{n}$ a aplicação em área total, e nas concentrações superiores a 0,0018\%, na aplicação dirigida, aos 30 DAA.
\end{abstract}

Palavras-chave: oxyfluorfen, Pilea microphylla, Zantedeschia aethiopica, Strelitzia reginae, Archontophoenix cunninghamiana.

ABSTRACT - This study aimed to evaluate efficacy of oxyfluorfen in controlling Pilea microphylla for the production of ornamental plant shoots. Two experiments were carried out in a randomized block design, arranged in a factorial scheme $2 \times 7$, with three replicates. One trial was composed by three ornamental plant species (Zantedeschia aethiopica, Strelitzia reginae and Archontophoenix cunninghamiana) and seven oxyfluorfen rates $(0,24,72,144,216,288$ and $\left.360 \mathrm{~g} \mathrm{ha}^{-1}\right)$, sprayed in a total area; the other trial was composed by the same species and seven oxyfluorfen concentrations (0.00000, 0.00036, 0.00072, 0.00144, 0.00288, 0.00576 and $0.01152 \%$ of a.i.) applied directly as spray, without reaching the ornamental plant leaves. Each experimental unit was represented by a pot with an ornamental plant shoot, infested with Pilea microphylla. At 15, 30 and 60 days after application (DAA) visual evaluations of the control on

Recebido para publicação em 23.2.2007 e na forma revisada em 31.8.2007.

2 Professor Adjunto - DCV/UFERS A, Dep. de Ciências Vegetais, Universidade Federal Rural do Semi-Árido, 59.625-900. Mossoró-MG, <fclaudiof@yahoo.com.br>; ${ }^{3}$ Professor Adjunto - DFT/UFV; ${ }^{4}$ Estudante de Agronomia - DFT/UFV; ${ }^{5}$ Professor Titular - DFT/UFV. 
P. microphylla and toxicity on ornamental plants were carried out. For the total area spray, the A. cunninghamiana plant pots demanded high herbicide doses due to this species'larger foliar area, during application, making the herbicide contact with weeds difficult. Still in this application modality, light intoxication symptoms were observed in the ornamental plants, being more evident in the A. cunning hamiana plants. For the direct spray modality, no interaction among the factors, species and herbicide concentration, nor herbicide behavior differences were observed for the characteristics evaluated. Intoxication was not observed in the ornamental plants in none of the treatments evaluated, for the direct spray modality. Efficient P. microphylla control was verified for rates above $90 \%$ at 300,320 and $340 \mathrm{~kg} \mathrm{ha}$ of oxyfluorfen, plants of $\mathbf{Z}$. aethiopica, S. reginae and $\boldsymbol{A}$. cunninghamiana, respectively, in total area application, and high concentrations over $0.0018 \%$, in the direct spray modality at $30 \mathrm{DAA}$.

Keywords: Oxyfluorfen, Pilea microphylla, Zantedeschia aethiopica, Strelitzia reginae, Archontophoenix cunninghamiana.

\section{INTRODUÇÃO}

O mercado brasileiro de flores e de plantas ornamentais tem apresentado expressivo crescimento econômico, produzindo em torno de dois bilhões de dólares anuais, representando $20 \%$ do total mundial, segundo levantamentos do Ibraflor em 2004. Aliado a isso, tem ocorrido expansão significativa do setor, além da geração de 50.000 empregos diretos e indiretos, o que é importante para o crescimento econômico e social do País (Junqueira, 2004).

A maioria das espécies de plantas ornamentais produzidas comercialmente, como a palmeira-australia na (Archontophoenix cunninghamiana), a estrelítzia (Strelitzia reginae) e o copo-de-leite (Zantedeschia aethiopica), apresenta na sua fase de desenvolvimento inicial (produção de mudas) taxa de crescimento lenta, quando comparada à verificada em algumas espécies de plantas daninhas, tornando-as vulneráveis à competição por água, luz e nutrientes.

Além disso, essas espécies precisam ser cultivadas, na fase de desenvolvimento inicial (palmeira-australiana e estrelitzia) ou durante todo o seu ciclo (copo-de-leite), em ambientes protegidos do excesso de radiação solar. Nessas condições, tem-se observado, comumente, a infestação de plantas daninhas, como a brilhantina (Pilea microphylla), planta perene, herbácea, prostrada, muito ramificada, com 10 a $20 \mathrm{~cm}$ de comprimento e que se propaga por sementes (Lorenzi, 2000). Essa planta afeta o desenvolvimento das mudas, aumentando o custo de produção e reduzindo o seu valor comercial.

O controle da brilhantina em vasos e sacolas de plantas ornamentais é realizado, normalmente, por meio de capina manual, podendo ocorrer rebrota caso a planta não seja totalmente eliminada, uma vez que ela emite, facilmente, novas brotações na região do coleto. Também, a produção elevada de sementes - que são de fácil transporte pelo vento e manuseio - promove rápida reinfestação (Freitas et al., prelo).

A utilização de herbicidas no controle de plantas daninhas em cultivo de plantas ornamentais, aliada a outras práticas de controle, é uma alternativa importante, reduzindo custos e melhorando a eficiência do processo produtivo (Freitas et al., prelo). Avaliando a seletividade e a eficácia de diversos herbicidas no controle da brilhantina em cultivo de bromélias, Freitas et al. (2004) verificaram que o oxyfluorfen controlou com eficiência as plantas de brilhantina, em aplicação dirigida, sem causar nenhuma toxidez nas plantas de bromélia. Em trabalho semelhante, conduzido com orquídeas, o oxyfluorfen também foi seletivo para esta espécie, em aplicação dirigida e em área total, promovendo excelente controle da brilhantina (Freitas et al., prelo).

O oxyfluorfen é um herbicida inibidor da enzima protoporfirinogênio oxidase (PROTOX) que, quando aplicado em pós-emergência, provoca fechamento estomático e deterioração das membranas celulares. Aplicado em préemergência, age sobre o hipocótilo e epicótilo 
das plantas em emergência e nos meristemas foliares, não apresentando nenhuma ação sobre os tecidos radiculares. A meia-vida no solo é de 30 a 40 dias, podendo apresentar efeito residual até seis meses depois da aplicação (Rodrigues \& Almeida, 2005). Sua degradação é essencialmente por fotólise, fazendo com que em áreas com condições de umidade e sombreamento seu período residual seja mais prolongado (Rodrigues \& Almeida, 2005; Cassamassimo, 2005).

A aplicação do oxyfluorfen pode ser feita de forma dirigida, procurando atingir apenas as espécies de plantas daninhas, ou em área total. A aplicação dirigida é mais indicada para situações em que o herbicida pode causar intoxicação na espécie de interesse econômico ou quando as folhas desta espécie promovem o "efeito guarda-chuva", dificultando o acesso das gotas pulverizadas ao alvo - no caso, as plantas daninhas (Freitas et al., no prelo).

Considerando a escassez de informações sobre o manejo de plantas daninhas em cultivo de plantas ornamentais, o objetivo deste trabalho foi avaliar a seletividade e a eficácia do oxyfluorfen no controle de brilhantina na produção de estrelítzia, copo-de-leite e palmeiraaustraliana.

\section{MATERIAL E MÉTODOS}

Foram conduzidos dois experimentos, sob telado de sombrite, com $50 \%$ de sombreamento, na Unidade de Floricultura do Departamento de Fitotecnia da Universidade Federal de Viçosa, onde foram avaliados dois métodos de aplicação do oxyfluorfen, no delineamento de blocos ao acaso, no esquema fatorial $3 \times 7$, com três repetições, entre os meses de janeiro e maio de 2005.

Um dos experimentos foi constituído por mudas de três espécies de plantas ornamentais (copo-de-leite, palmeira-australiana e estrelítzia) e sete doses de oxyfluorfen $(0,24$, $72,144,216,288$ e $360 \mathrm{~g} \mathrm{ha}^{-1}$ ) pulverizadas em área total, e o outro, pelas mesmas espécies e sete concentrações de oxyfluorfen $(0,0,00036$, $0,00072, \quad 0,00144,0,00288,0,00576$, 0,01152\% do i.a.), aplicadas em pulverização dirigida à brilhantina, sem atingir as folhas das mudas das plantas ornamentais. Cada unidade experimental foi constituída de um vaso perfurado, com capacidade de um litro, contendo uma muda de planta ornamental, infestado com brilhantina (Figura 1). O substrato utilizado foi composto de solo (LVA) (50\%), areia lavada (25\%) e composto orgânico $(25 \%)$, adubado com $3 \mathrm{~kg}$ de superfosfato simples por $\mathrm{m}^{3}$ da mistura. A cada 14 dias, cada vaso foi adubado em cobertura com $0,5 \mathrm{~g}$ da formulação 20-05-20 (N-P-K) por vaso.

No experimento cuja aplicação do oxyfluorfen foi realizada em área total, utilizou-se pulverizador costal, mantido à pressão constante pelo $\mathrm{CO}_{2}$, equipado com barra com dois bicos XR 11002 , espaçados de $50 \mathrm{~cm}$, mantidos à altura de $50 \mathrm{~cm}$ do alvo, à pressão de $250 \mathrm{kPa}$, com volume de calda de $200 \mathrm{~L} \mathrm{ha}^{-1}$.

No experimento com aplicação dirigida do oxyfluorfen, foi utilizado também o pulverizador costal, mantido à pressão constante pelo $\mathrm{CO}_{2}$, equipado com um bico de cone vazio, modelo TX 8002, à pressão de $200 \mathrm{kPa}$. A aplicação da calda foi direcionada, procurando atingir somente as plantas de brilhantina, molhando até o ponto de pré-escorrimento e evitando o contato das gotas com as folhas das mudas das plantas ornamentais.

No momento da aplicação, a temperatura e umidade relativa do ar eram, respectivamente, de $25^{\circ} \mathrm{C}$ e $85 \%$, e a velocidade do vento, de $2 \mathrm{~km} \mathrm{~h}^{-1}$. As mudas de copo-de-leite, palmeiraaustraliana e estrelítzia estavam com 15 a $20 \mathrm{~cm}$ de altura, e a brilhantina, com cerca de $5 \mathrm{~cm}$ (Figura 1).

Aos 15, 30 e 60 dias após aplicação do herbicida (DAA) foram realizadas avaliações visuais de controle de brilhantina, usando a escala de 0 (ausência de toxidez) a 100 (morte das plantas), e de intoxicação nas mudas de plantas ornamentais, utilizando-se a escala de 1 a 4 , em que 1 representa ausência de intoxicação; 2, intoxicação leve; 3 , intoxicação moderada; e 4, intoxicação severa.

Em ambos os experimentos, os dados de controle de brilhantina obtidos foram submetidos às análises de variância de regressão. Os modelos adotados foram devido à explicação biológica, à significância do quadrado médio da regressão e ao coeficiente de regressão. 

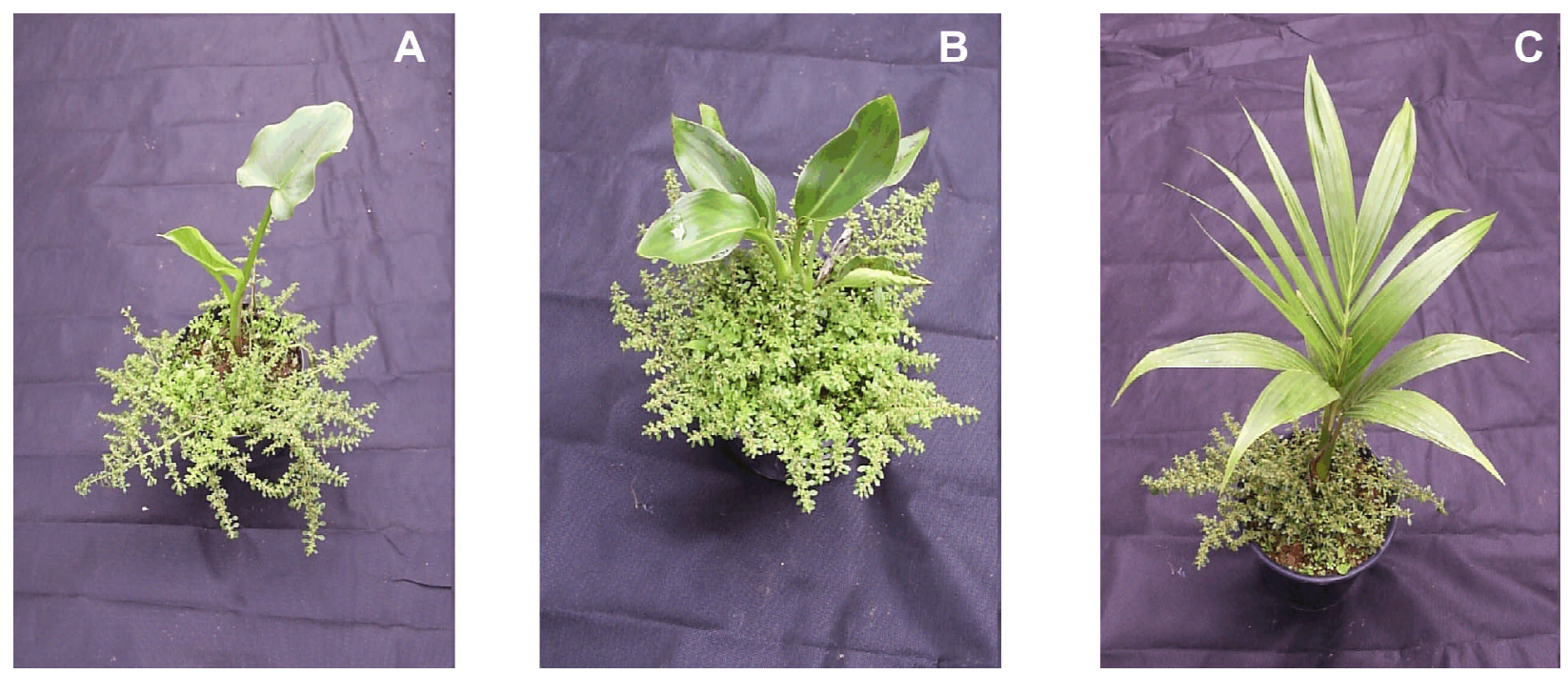

Figura 1 - Vasos de copo-de-leite (A), estrelítzia (B) e palmeira-australiana (C) na ocasião da aplicação do herbicida.

\section{RESULTADOS E DISCUSSÃO}

No experimento em que a aplicação do oxyfluorfen foi feita na área total, verificou-se diferença significativa, a $5 \%$ de probabilidade, pelo teste F, para os fatores dose e espécies de plantas ornamentais, bem como para a interação entre eles, no controle da brilhantina. Com isso, foram feitos os desdobramentos para o estudo das doses dentro de cada espécie.

Verificou-se controle de brilhantina, superior a $90 \%$, a partir das doses de: $300 \mathrm{~g}^{\text {ha-1 }} \mathrm{de}^{-}$ oxyfluorfen, aos 30 e 60 DAA, nos vasos de copo-de-leite (Figura 2); 320 e $300 \mathrm{~g}_{\text {ha }}{ }^{1}$ de oxyfluorfen, respectivamente, aos 30 e 60 DAA, nos vasos de estrelítzia (Figura 3); e 340 e $350 \mathrm{~g} \mathrm{ha}^{-1}$ de oxyfluorfen, respectivamente, aos 30 e 60 DAA, nos vasos de palmeira-australiana (Figura 4). Esses resultados são semelhantes aos encontrados por Freitas et al. (prelo), avaliando o controle da mesma espécie em vasos de orquídea, os quais verificaram controle superior a $90 \%$ a partir de 260 e $250 \mathrm{~g} \mathrm{ha}^{-1}$ de oxyfluorfen, respectivamente, aos 30 e 60 DAA. Avaliando o mesmo herbicida na cultura da cebola em semeadura direta, Ferreira et al. (2000) constataram controle eficiente de Amaranthus hybridus e Galinsoga parviflora a $192 \mathrm{~g} \mathrm{ha}^{-1}$, dose esta que não foi eficiente no controle de Lepidium verginicum e Coronopus didymus, aos 58 DAA. Alves et al. (2000) verificaram intoxicação em plantas de milho, em simulação de deriva, em aplicação realizada aos 14 dias após emergência da cultura, a partir de $288 \mathrm{~g} \mathrm{ha}^{-1}$ de oxyfluorfen. Entretanto, a produtividade da cultura só foi afetada com a aplicação de doses superiores a $0,178 \mathrm{~L} \mathrm{ha}^{-1}$.

A necessidade de doses superiores para controle da brilhantina em vasos de palmeiraaustraliana (Figura 4), em relação aos de copode-leite e estrelítiza (Figuras 2 e 3), foi, provavelmente, conseqüência da maior área foliar e disposição das folhas desta espécie, na ocasião da aplicação (Figura 1), promovendo "efeito guarda-chuva", que impede o acesso de parte das gotas pulverizadas às plantas daninhas. Segundo Freitas et al. (prelo), a aplicação em área total é mais indicada para plantas de menor porte e/ou sem área foliar expressiva, a fim de evitar o "efeito guarda-chuva".

Ainda no tocante aplicação em área total, verifica-se na Tabela 1 que as mudas de palmeira-australiana foram as que apresentaram maior intoxicação causada pelo oxyfluorfen, sobretudo nas doses mais elevadas, caracterizada por necrose nas folhas mais novas. As mudas de copo-de-leite e estrelítzia foram pouco afetadas pelo herbicida, não mostrando nenhum sintoma de intoxicação aos $30 \mathrm{e}$ 60 DAA, respectivamente, para os tratamentos nos quais foi obtido controle eficiente da espécie infestante. A recuperação mais rápida 


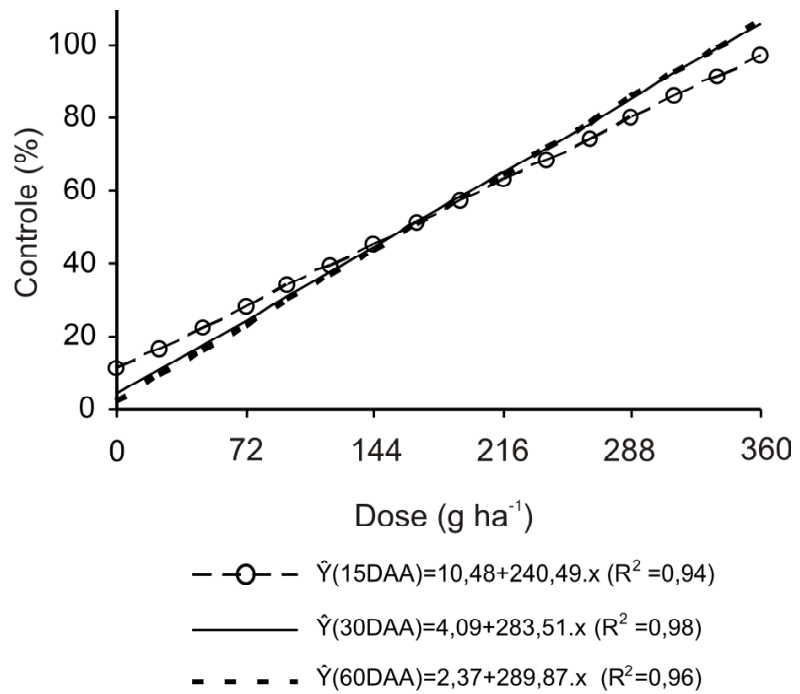

Figura 2 - Controle de brilhantina em vasos de copo-de-leite, em função das doses de oxyfluorfen, aplicadas em área total, para avaliações realizadas aos 15, 30 e 60 dias após aplicação (DAA).

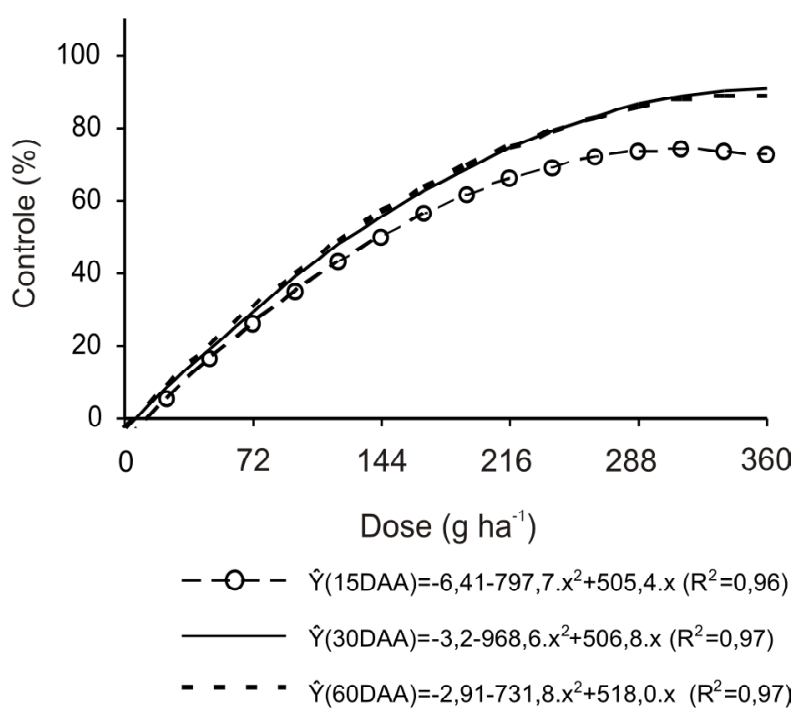

Figura 4 - Controle de brilhantina em vasos de palmeiraaustraliana, em função das doses de oxyfluorfen, aplicadas em área total, para avaliações realizadas aos 15, 30 e 60 dias após aplicação (DAA).

das plantas de copo-de-leite, principalmente em relação à palmeira-australiana, se deve, entre outros fatores, à sua taxa de crescimento mais rápida, com a emissão de novas folhas. Segundo Alves et al. (2000), os efeitos de fitotoxicidade observados para este

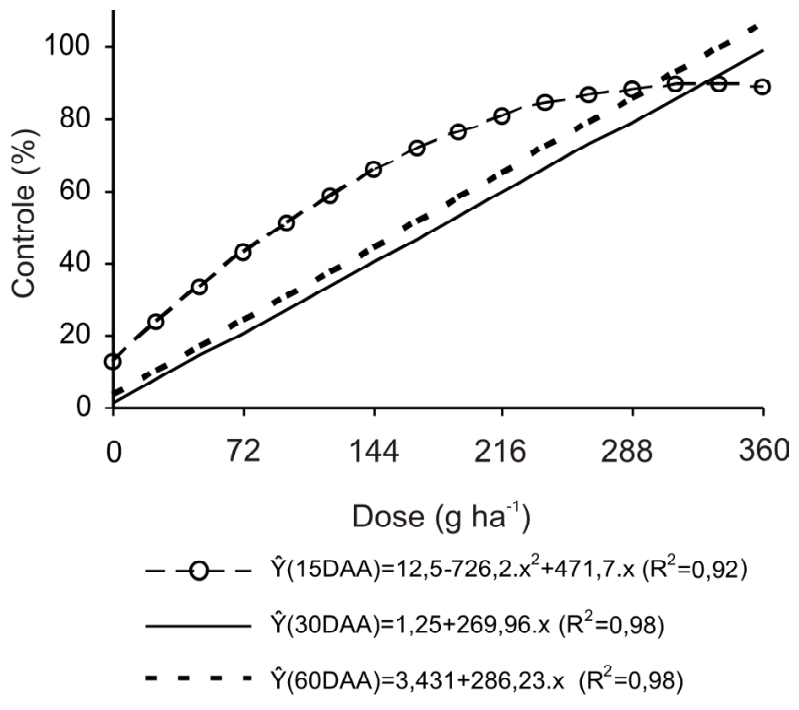

Figura 3 - Controle de brilhantina em vasos de estrelítzia, em função das doses de oxyfluorfen, aplicadas em área total, para avaliações realizadas aos 15, 30 e 60 dias após aplicação (DAA).

herbicida ficam restritos aos locais de contato entre o produto e a planta, não havendo evolução dos efeitos com o desenvolvimento das plantas.

Avaliando a seletividade de herbicidas sobre mudas de Myracrodruon urundeuva, Duarte et al. (2006) verificaram, aos 14 DAA, sintomas leves de intoxicação para doses de 720 e $1.400 \mathrm{~g} \mathrm{ha}^{-1}$ de oxyfluorfen. Contudo, aos 28 DAA, não se verificou nenhuma intoxicação nas plantas tratadas com a menor dose.

No experimento realizado com aplicação dirigida de oxyfluorfen, o comportamento do herbicida foi semelhante nas três espécies de plantas ornamentais estudadas, não tendo sido observada interação significativa entre fatores, espécie e concentração do herbicida, para controle de brilhantina. Portanto, os dados apresentados foram obtidos a partir da média das três espécies de plantas ornamentais.

$\mathrm{Na}$ Figura 5, observa-se controle de brilhantina acima de $90 \%$ a partir das concentrações de 0,0018 e $0,0016 \%$ de oxyfluorfen, aos 30 e 60 DAA, respectivamente. Esses resultados são semelhantes aos verificados por Freitas et al. (prelo), que foram de 0,0020 e $0,0019 \%$ de oxyfluorfen, aos 30 e 60 DAA, respectivamente, em vasos de cultivo de 
Tabela 1 - Níveis de intoxicação observados nas plantas de copo-de-leite, estrelítzia e palmeira-australiana para avaliações realizadas aos 15, 30 e 60 dias após aplicação (DAA), no experimento com aplicação de oxyfluorfen em área total

\begin{tabular}{|c|c|c|c|c|c|c|c|c|c|}
\hline \multirow{2}{*}{$\begin{array}{c}\text { Dose } \\
\left(\mathrm{g} \mathrm{ha}^{-1}\right)\end{array}$} & \multicolumn{3}{|c|}{ Copo-de-leite } & \multicolumn{3}{c|}{ Estrelítzia } & \multicolumn{3}{c|}{ Palmeira-australiana } \\
\cline { 2 - 10 } & 15 DAA & 30 DAA & 60 DAA & 15 DAA & 30 DAA & 60 DAA & 15 DAA & 30 DAA & 60 DAA \\
\hline 0 & $1,0 *$ & 1,0 & 1,0 & 1,0 & 1,0 & 1,0 & 1,0 & 1,0 & 1,0 \\
\hline 24 & 1,0 & 1,0 & 1,0 & 1,0 & 1,0 & 1,0 & 1,6 & 1,8 & 1,0 \\
\hline 72 & 1,0 & 1,0 & 1,0 & 1,6 & 1,0 & 1,0 & 1,4 & 1,3 & 1,7 \\
\hline 144 & 1,5 & 1,0 & 1,0 & 2,4 & 1,0 & 1,0 & 1,2 & 1,6 & 1,8 \\
\hline 216 & 2,0 & 1,0 & 1,0 & 2,4 & 1,7 & 1,0 & 1,4 & 1,9 & 2,2 \\
\hline 288 & 2,2 & 1,0 & 1,0 & 2,7 & 2,7 & 1,0 & 2,5 & 2,7 & 2,3 \\
\hline 360 & 2,7 & 1,0 & 1,0 & 2,7 & 2,7 & 1,2 & 2,0 & 2,3 & 2,8 \\
\hline
\end{tabular}

* Escala de intoxicação nas mudas de plantas ornamentais: ausência (1), leve (2), moderada (3) e severa (4).

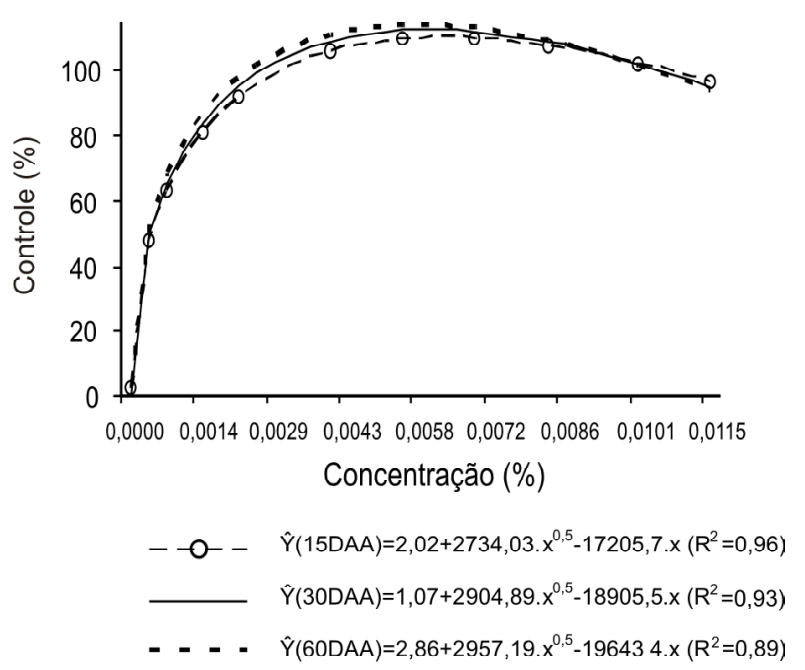

Figura 5 - Controle de brilhantina em vasos de copo-de-leite, estrelítzia e palmeira-australiana, em função das concentrações de oxyfluorfen, em aplicação dirigida, para avaliações realizadas aos 15, 30 e 60 dias após aplicação (DAA).

orquídeas, e inferiores aos obtidos por Freitas et al. (2004), que foram de 0,0192 e 0,0168\%, respectivamente, aos 20 e 60 DAA, em vasos de cultivo de bromélia, para controle de brilhantina.

Quando aplicado na forma de jato dirigido, o oxyfluorfen não causou intoxicação nas mudas de nenhuma das espécies de plantas ornamentais, nas avaliações feitas aos 15, 30 e 60 DAA (Tabela 2). Esses resultados corroboram os de Freitas et al. (2004) e Freitas et al. (prelo), que também não constataram nenhuma intoxicação em plantas de bromélias e orquídeas, respectivamente, em aplicação dirigida desse herbicida.

Além da eficiência verificada no controle da brilhantina, o oxyfluorfen evitou a reinfestação durante o período experimental, por apresentar bom efeito residual no substrato. Segundo Rodrigues \& Almeida (2005), o efeito residual do oxyfluorfen é mais prolongado em ambiente com umidade elevada e protegido da incidência de raios solares, uma vez que sua principal rota de degradação é a fotólise. Também, Cassamassimo (2005), avaliando a dissipação de oxyfluorfen em solos com atividades florestais, sombreados e a pleno sol, verificou dissipação mais lenta do herbicida nas áreas sombreadas. Yen et al. (2003) verificaram que temperaturas elevadas aumentam a taxa de dissipação do oxyfluorfen. Assim, sua ação, neste trabalho, pode ter sido potencializada, visto que o substrato nos vasos foi mantido em ambiente protegido, com $50 \%$ de sombreamento, e umidade em torno de $80 \%$ da capacidade de campo, mantida por meio de irrigações diárias.

Os resultados mostraram que o método de aplicação em área total é mais indicado para casos em que a área foliar das plantas de interesse econômico, no momento da aplicação, não prejudique o acesso das gotas pulverizadas à planta daninha, desde que a espécie cultivada seja tolerante à aplicação foliar do herbicida, enquanto a aplicação dirigida é mais adequada para espécies sensiveis à aplicação foliar e/ou que possuam área foliar impressiva, promovendo o "efeito guarda-chuva". Freitas et al. (prelo) também recomendam a aplicação dirigida como estratégia para evitar 
o "efeito guarda-chuva", apesar de ser um processo bem mais moroso.

\section{LITERATURA CITADA}

ALVES, L. W. R.; SILVA, J. B.; SOUZA, I. F. Efeito da aplicação de subdoses dos herbicidas glyphosate e oxyfluorfen, simulando deriva sobre a cultura de milho (Zea mays L.). Ci. Agrotec., v. 24, n. 4, p. 889-897, 2000.

CASSAMASSIMO, R. E. Dissipação e mobilidade dos herbicidas gliphosato e oxyfluorfen em solos com atividades florestais. $200562 \mathrm{f}$. Dissertação (Mestrado em Recursos Florestais) - Escola Superior de Agricultura Luiz de Queiroz, Piracicaba, 2005.

DUARTE, N. F. et al. Seletividade de herbicidas sobre Myracrodruon urundeuva (aroeira). Planta Daninha, v. 24, n. 2, p. 329-337, 2006.

FERREIRA, L. R. et al. Seletividade e eficácia da aplicação de seqüencial de oxyfluorfen e de ioxynil-octanoato, em semeadura direta de cebola. Planta Daninha, v. 18, n. 1, p. $3950,2000$.
FREITAS, F. C. L. et al. Controle químico de plantas daninhas em bromeliários. In: CONGRESSO BRASILEIRO DA CIÊNCIA DAS PLANTAS DANINHAS, 24., 2004, São Pedro. Resumo Expandido... São Pedro: 2004. CD-ROM.

FREITAS, F. C. L. et al. Controle químico de brilhantina (Pilea microphylla) no cultivo de orquíde as. Planta Daninha, v. 25, n. 3, p. 589-593, 2007.

JUNQUEIRA, A. H. Evolução das exportações brasileiras de flores e plantas ornamentais até agosto de 2004.

Disponível em: 〈www.ibraflor.com.br〉.

LORENZI, H. Plantas daninhas do Brasil: terrestres, aquáticas, parasitas e tóxicas. 3.ed. Nova Odessa: Instituto Plantarum, 2000. 608 p.

RODRIGUES, B. N.; ALMEIDA, F. S. Guia de

herbicidas. 3.ed. Londrina: IAPAR, 2005. 591 p.

YEN, J. H.; SHEU, W. S.; WANG, Y. S. Dissipation of the herbicide oxifluorfen in subtrolical soils and its potential to contaminate groundwater. J. Ecotoxicol. Environ. Safety, v. 54, n. 2, p. 151-156, 2003. 